\title{
A ERA DA DEMOCRACIA CONFUSA: ANÁLISE DAS MEDIDAS DE ADESÃO À DEMOCRACIA NAS PESQUISAS SOBRE COMPORTAMENTO POLÍTICO ${ }^{12}$
}

\author{
Renata Andrade de Oliveira ${ }^{3}$
}

\begin{abstract}
RESUMO
No panorama atual da Ciência Política há a insistência em se afirmar a "profissão de fé democrática", pressupondo a existência de um conceito universal do termo. Contudo, as múltiplas fontes nas quais a democracia moderna se fundamenta denotam um caráter polissêmico ao conceito. Por isso, um dos principais duelos da teoria política é a oposição entre suas funções procedimental e normativa. Tal dualidade está presente nas pesquisas acadêmicas em estudos que focam, de um lado, na análise empírica da aplicabilidade do conceito e, do outro, nos debates teóricos do processo democrático. Por isso, a questão central deste artigo é saber quais os conceitos de democracia utilizados nos estudos mais recentes sobre comportamento político. Para tanto, criamos um panorama sobre o que as pesquisas comportamentais têm realmente mensurado como fatores de adesão à democracia (estudos sobre legitimidade democrática). Após a análise de alguns artigos foi possível observar que há uma desconexão entre a teoria política e as pesquisas empíricas a esse respeito. No geral, os estudos buscam a mensuração da instrumentalidade do processo, sendo poucos os que pensam a multidimensionalidade da democracia. Assim, esse descompasso torna necessário repensar as medidas de adesão à democracia na área de comportamento político, visando o alinhamento entre o que se tem produzido na teoria democrática e o que se descreve nas pesquisas empíricas.
\end{abstract}

Palavras-chave: Democracia. Adesão à democracia. Comportamento político. Metodologia.

\begin{abstract}
On the current panorama in Political Science is the insistence on affirming the "profession of democratic faith", presupposing the existence of a universal concept of democracy. However, the multiple sources on which modern democracy is based denote a polysemic character to the concept. For this reason, one of the main duels of political theory is the opposition between its procedural and normative functions. Such duality is present in academic research, in studies that focus, on the one hand, on the empirical analysis of the applicability of the concept and, on the other hand, on the theoretical debates of the democratic process. Around this, the central question of this article is to know what concepts of democracy are used in the most recent studies of political behavior. In order to do so, we create an overview of what behavioral research has actually measured as factors of adherence to democracy (studies of democratic legitimacy). After analyzing some articles, it was possible to observe that there is a disconnection between political theory and empirical research. In general, the studies seek to measure the instrumentality of the process, few of which think of the multidimensionality of democracy. Therefore, this imbalance makes it necessary to rethink the measures of adherence to democracy in the area of political behavior, aiming the alignment between what has been produced in democratic theory and what is described in empirical research.
\end{abstract}

Keywords: Democracy. Adherence to democracy. Political Behavior. Methodology.

\section{RESUMEN}

En el panorama actual de la ciencia política existe la insistencia en afirmar la "profesión de fe democrática", presuponiendo la existencia de un concepto universal del termo. Sin embargo, las múltiples fuentes en las que la democracia moderna se fundamenta denotan un carácter polisémico al concepto. Por eso, uno de los principales duelos de la teoría política es la oposición entre sus funciones procedimental y normativa. Esta dualidad está presente en las investigaciones académicas en estudios que se centran, por un lado, en el análisis empírico de la aplicabilidad del concepto y, por otro, en los debates teóricos del proceso democrático. Por eso, la cuestión central de este artículo es saber cuáles son los conceptos de democracia utilizados en los estudios más recientes sobre comportamiento político. Para esto creamos un panorama sobre lo que las investigaciones comportamentales han medido realmente como factores de adhesión a la democracia (estudios sobre legitimidad democrática). Después del análisis de algunos

\footnotetext{
${ }^{1}$ DOI: http://dx.doi.org/10.5380/recp.v8i2.56296

2 Submetido em: 30 de setembro de 2017. Aprovado em: 15 de outubro de 2017.

${ }^{3}$ Doutoranda do Programa de Pós-Graduação em Sociologia Política (PPGSP) da Universidade Federal de Santa Catarina (UFSC); Mestra em Ciências Sociais pela Universidade Estadual de Maringá (UEM-PR). E-mail: rehnata_andrade@hotmail.com.
} 
OLIVEIRA, R. A. A era da democracia confusa: Análise das medidas de adesão à democracia nas pesquisas sobre comportamento político

artículos fue posible observar que hay una desconexión entre la teoría política y las investigaciones empíricas. En general, los estudios buscan la medición de la instrumentalidad del proceso, siendo pocos los que piensan la multidimensionalidad de la democracia. Así, ese descompaso hace necesario repensar las medidas de adhesión a la democracia en el área de comportamiento político, visando la alineación entre lo que se ha producido en la teoría democrática y lo que se describe en las investigaciones empíricas.

Palabras clave: Democracia. Adhesión a la democracia. Comportamiento político. Metodología.

\section{INTRODUÇÃO}

Muitas sociedades ocidentais vivenciaram, pós-Guerra Fria, o movimento de democratização, o que fez com que o termo "democracia" passasse a ser usado com maior frequência. Por conta disso, atualmente o panorama que se observa é a chamada "profissão de fé democrática" (SILVA, 1999), na qual o termo é utilizado sem ao menos denotar um sentido real para ele, pressupondo a existência de um conceito universal. Tal movimento é comumente observável no ambiente acadêmico, onde diversos estudos não delimitam o conceito no qual se baseiam, o que leva ao silenciamento sobre seus significados, dando uma conotação consensual ao termo.

Entretanto, estamos longe da unificação da definição da democracia em um sentido universal e condizente com todas as realidades, e, muito menos, produto de acordo entre as teorias democráticas (SILVA, 1999; LAVALLE; VERA, 2011). Um dos fatores que contribui para esse cenário seria a expansão da ideia de democracia como regime central no século XX, pois gerou grandes divergências entre os teóricos em razão de seus procedimentos e instituições, o que se refletiu em entraves para a compreensão de uma feição mínima sobre a definição do termo (LAVALLE; VERA, 2011).

Nesse sentido, a indeterminação do conceito advém justamente das múltiplas fontes nas quais a democracia moderna se fundamenta (SILVA et al., 2013), o que denota um caráter polissêmico ao seu significado. Sendo o termo fruto das próprias tensões presentes nas teorias democráticas, Silva (1999) aponta que tais conflitos internos passaram a ser vistos como impurezas analíticas que trariam complexidade aos elementos constitutivos do conceito de "democracia". Por isso, alguns teóricos têm buscado abandonar esse caminho, em prol de uma visão simplista, mas enganosa, uma vez que gera oposição e polarização entre os elementos do sistema democrático (sendo que todos eles são constituintes do mesmo fenômeno).

Entre os principais debates da teoria democrática contemporânea, destacamos a oposição que tem se firmado entre a função procedimental e a normativa da democracia. Essa dualidade é presença constante nas pesquisas acadêmicas, tanto em estudos que se debruçam sobre os debates

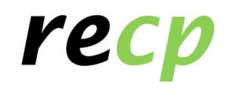


teóricos do processo democrático, quanto em estudos que focam na análise empírica da aplicabilidade do conceito. Desse modo, é importante verificar se essas duas áreas da Ciência Política seguem caminhos paralelos, motivo pelo qual devemos olhar o modo como os estudos empíricos têm avaliado os aspectos fundamentais da democracia. Nesse sentido, a área de comportamento político torna-se interessante objeto de análise, uma vez, que constrói medidas para avaliar a adesão dos indivíduos à democracia — os chamados "estudos sobre legitimidade".

Os estudos sobre comportamento político ganharam força nas últimas décadas, especialmente aqueles sobre cultura política, adesão à democracia ${ }^{4}$ e comportamento eleitoral. A importância de se estabelecer uma análise conceitual se fundamenta no fato de que o termo "democracia" tem se replicado nessas pesquisas, e o modo como ele é utilizado acaba por influenciar na forma como os elementos são mensurados, permitindo conclusões que classifiquem grupos ou países em mais ou menos democráticos. Todavia, são poucos os autores que demarcam sobre qual democracia estão falando: em sua maioria os trabalhos deixam o conceito como algo já teoricamente implícito para o leitor. Por essa razão, torna-se de extrema relevância buscar compreender como a democracia tem sido avaliada e definida por essa área da Ciência Política.

Em torno disso, o objetivo desse artigo é verificar qual o conceito de "democracia" presente nos estudos de viés comportamental, em especial nos pautados em pesquisas de survey ${ }^{5}$ - ou seja, verificar o que realmente tem sido avaliado como comportamento democrático. Assim, na primeira parte do artigo serão expostas as linhas teóricas mais tradicionais, que apontam definições de democracia pautadas em fontes diversas. Após delimitar o campo teórico, iremos nos debruçar na avaliação das medidas utilizadas mais recentemente para analisar a democracia, através dos estudos sobre legitimidade democrática. Por fim, será proposta uma classificação para essas medidas a partir das definições teóricas e, assim, observado qual conceito está mais presente nas análises empíricas e como isto se relaciona com o processo de comunicação entre teoria e empiria.

\footnotetext{
${ }^{4}$ No presente artigo utilizaremos como equivalentes os termos "adesão à democracia" e "apoio à democracia", ambos utilizados pelos estudos sobre legitimidade democrática.

${ }^{5}$ A maioria das pesquisas na área do comportamento político utilizam survey já aplicados por alguma instituição internacional; assim, já possuem questionários pré-estabelecidos. Dessa forma, é importante verificar quais medidas em favor da democracia estão sendo disponibilizadas mundialmente.
} 
OLIVEIRA, R. A. A era da democracia confusa: Análise das medidas de adesão à democracia nas pesquisas sobre comportamento político

\section{AFINAL O QUE É DEMOCRACIA?}

Desde o século XVIII, o tema "democracia" vem sendo a problemática central da política e da Ciência Política (REIS, 2000). Isto porque a expansão das ideias e crenças democráticas e os processos implicados nessa etapa converteram essa temática em um lugarcomum no pensamento político. Em diversos debates a palavra "democracia" é utilizada de maneira corriqueira, sem que haja necessidade de seu interlocutor explicar o seu sentido, pois há a pressuposição de um consenso sobre seu significado. Ocorre que estamos distantes de um consenso em torno de sua definição, como apresenta Sartori (1994); vivemos em plena "era da democracia confusa”, onde há grande indeterminação a respeito do conceito, devido às múltiplas fontes nas quais se fundamenta a democracia moderna. Dessa forma, o conceito de "democracia" é dotado de polissemia e tensões em relação aos seus elementos.

Para as pretensões aqui existentes, o foco teórico estará no debate entre correntes mais opostas da teoria democrática, exemplificadas por alguns autores. O ponto de partida serão as críticas efetuadas à definição de alguns teóricos elitistas ${ }^{6}$ de que a democracia deveria estar desvinculada do caráter valorativo, não sendo central o valor em si, e sim as práticas democráticas. Um desses teóricos é Joseph Schumpeter. Para o autor da obra "Capitalismo, Socialismo e Democracia”, a doutrina clássica preocupava-se com como a democracia deveria ser, e não com como ela era de fato; por conta disso, vivia uma ilusão baseada em mitos que não representavam a realidade das sociedades democráticas. Para ele, não havia nada na realidade empírica que pudesse ser identificado como bem comum ou vontade popular, pois qualquer visão sobre estes seria construída pela própria política. Por isso, a democracia deveria abandonar o “dever ser” e se concentrar na análise sobre "o que é” (SCHUMPETER, 1961).

O resultado da crítica schumpeteriana foi a elaboração de uma nova teoria da democracia, essencialmente mais empírica e realista em seus termos. Seus argumentos desenvolviam as ideias de que a democracia deveria estar desvinculada de um caráter normativo e de que o centro das atenções teóricas deveria ser o modelo democrático, enquanto processo e ferramentas práticas. O autor via a necessidade de se operacionalizar o conceito de "democracia",

\footnotetext{
${ }^{6}$ Utiliza-se a argumentação de Luís Felipe Miguel (2014) de que “[...] a democracia e o liberalismo compartilha [sic] um entendimento igualitário. [...] o ideal liberal se funda numa crença da igual capacidade de cada um buscar o próprio interesse e governar a própria vida. [...] Assim, o que caracteriza a corrente hegemônica da teoria democrática não tanto seu caráter liberal, que pouco a diferencia, mas seu caráter elitista".
} 
atribuindo-lhe determinada forma (de adquirir poder) e função (tomada de decisões políticas) para o processo político (RANINCHESKI; CASTRO, 2012). Neste sentido, o formato torna-se eixo central para a construção do método democrático, visto como principal característica da democracia, afastada dos aspectos substantivos (RANINCHESKI; CASTRO, 2012).

A teoria de Schumpeter analisa a democracia como um método para formar governos. Trata-se de um acordo institucional, sem que possa repercutir valores. Por conta disso, o processo eleitoral passa a ser o principal meio e a democracia representativa, através do sistema do voto, o método democrático. Vale ressaltar que o objeto valorizado, neste caso, é o modo como a democracia se faz por meio do processo eleitoral, não havendo relevância no valor do voto e no papel dos indivíduos. O que Schumpeter propõe é que o povo seja produtor do governo; o papel do indivíduo ou do "povo" resume-se a votar e escolher seus governantes, cabendo às elites governar, sendo o voto apenas parte do processo.

Mesmo apresentando alguns pontos fortes passíveis de críticas, a teoria de Schumpeter é vista por alguns autores como um divisor de águas para a teoria democrática (SILVA, 1999; SILVA et al., 2013). Sua posição executa uma ruptura em relação à dimensão clássica da democracia de caráter mais valorativo e propõe um modelo mais realista. Assim, "tal ruptura deve ser vista como a tentativa de afastamento dos 'ideais normativos' de democracia em favor de um debate puramente 'empirista' sobre prática de governo" (SILVA et al., 2013). Sendo assim, sua teoria representa um marco do procedimentalismo, ao visualizar a democracia como um arranjo institucional de tomada de decisões.

A teoria da poliarquia de Robert Dahl (1997), por exemplo, possui pontos em comum com as críticas de Schumpeter aos clássicos: ambos acreditam na forma real da existência da democracia como base para uma teoria democrática mais empírica e instrumental. Entretanto, seus caminhos se opõem quando Dahl afirma que a democracia não pode ser limitada ou definida apenas como um procedimento ou um meio para decisões políticas. Pelo contrário, afirma ser importante a presença de valores como igualdade política, liberdade de voto, organização e expressão, alternância de mandatários resultantes da escolha dos eleitores, participação política e justiça (DAHL, 2008).

Por conta de seu posicionamento que tenta mesclar o caráter normativo ao valorativo, Dahl assume uma democracia mais plural, pautada em um método político fundamentado em princípios democráticos, o que torna a aplicação desse modelo teórico mais 
OLIVEIRA, R. A. A era da democracia confusa: Análise das medidas de adesão à democracia nas pesquisas sobre comportamento político

abrangente. O pluralismo, para o teórico, estaria presente na democracia, que conseguiria descentralizar e dividir o poder entre diferentes grupos e que possuiria espaços de discussão e confrontação de ideias. Em outras palavras, seu modelo de democracia possibilitaria um alto nível de participação e de contestação, devido ao aumento da concorrência pelo poder. Isto mostra que a sua preocupação está na construção de um modelo de sistema político que distribua o poder e promova a competição (DAHL, 1997).

Nesse sentido, a efetividade de uma democracia mais plural está fundada na possibilidade de todos participarem de maneira igual do sistema e dos processos políticos. Entretanto, é preciso que a arena política se torne um lugar com estrutura e procedimentos que possibilitem a inclusividade (utilizando os termos do próprio Dahl) dos indivíduos e de grupos na política, para que assim ocorram disputas justas e iguais (DAHL, 1997, 2008). Sendo assim, as instituições ganham papel relevante na garantia e no respeito aos direitos por parte dos governantes.

Entretanto, autores como Bachrach (1973), Pateman (1992) e Young (2000, 2005) são críticos assíduos da abordagem de acordo com a qual a democracia é pensada de forma procedimental e ausente de caráter valorativo. Para eles, a democracia é complexa demais para se limitar aos processos políticos e deve ser pensada através de seus ideais e de suas bases normativas, já que estes estão presentes na essência das práticas políticas. Seguindo essas críticas, a mudança de parâmetros de análise, saindo de um conceito limitado a procedimentos com modelos que exaltam a necessidade da retomada dos valores democráticos, fez com que outros autores também emergissem para o debate.

Simultaneamente, outras tendências teóricas foram se firmando a partir dos processos de democratização e das inovações institucionais, tais como Jürgen Habermas (2001), Alain Touraine (1996) e Carole Pateman (1992). Cada um concentrou seu discurso em um aspecto que julgava ser fundamental para uma sociedade democrática, como a comunicação e a participação política. Entretanto, todos são críticos das teorias democráticas puramente normativas ou procedimentais, e seus pensamentos se encontram na ideia de que a democracia em seu mais alto grau deve ser composta por um sistema político e eleitoral que tenha instituições e regras

\footnotetext{
${ }^{7}$ O principal vetor da inclusividade seria o sufrágio universal, e esta conquista de direitos é importante dentro da proposta da poliarquia, já que o voto é um fator de relevância para que uma sociedade democrática possua um sistema eleitoral com eleições regulares e livres.
} 
responsáveis pela organização da política, ao mesmo tempo em que promovam os valores básicos, como igualdade, justiça e liberdade.

Para Pateman (1992), por exemplo, as instituições não podem ser descoladas dos indivíduos. Assim, se os processos promovem mais participação, possibilita-se a formação de cidadãos mais democráticos, pois propagam-se os valores da democracia. A teoria habermasiana tenta resgatar a "cultura cívica" mais democrática (RANINCHESKI; CASTRO, 2012) que se tem perdido e, por isso, foca na função desempenhada pela esfera pública nesse procedimento. Nessas abordagens, a democracia é vista como um sistema constituído de valores que depende da existência de espaços públicos, que são produzidos pelas instituições democráticas em suas formalidades. Portanto, a partir desse ponto em comum - o distanciamento do procedimentalismo de Schumpeter, mas sem se ater apenas ao caráter normativo —, estes autores se juntam a Dahl em prol de uma democracia mista.

As principais correntes de pensamento democrático do século XX foram expostas acima no intuito de demonstrar que o conceito de "democracia" não é tão simples ou consensual, posto que cada autor enfatiza aspectos que considera mais determinantes. Mesmo com suas divergências, todos esses autores tinham a preocupação de analisar a democracia em um patamar mais empírico (BONIFACIO, 2013). Em prol do objetivo do artigo - compreender qual democracia tem sido empiricamente mensurada nos estudos sobre comportamento político —, estabelecemos possíveis dimensões de classificação para as medidas utilizadas. Porém, primeiramente, iremos expor na próxima seção algumas medidas que foram utilizadas em estudos mais recentes.

\section{COMPORTAMENTO POLÍTICO E MEDIDAS DE APOIO À DEMOCRACIA}

Os estudos sobre comportamento político não começaram recentemente, mas apenas nos últimos têm se consolidado como uma área de pesquisa dentro da Ciência Política no Brasil. Em 2010 houve a criação da sessão temática de comportamento político no Encontro Anual da Associação Nacional de Pós-Graduação e Pesquisa em Ciências Sociais (ANPOS) e, desde o primeiro encontro da Associação Brasileira de Ciência Política (ABCP), em 2012, existem sessões sobre o tema dentro da área temática de Cultura política e democracia. Além disso, existem grupos de pesquisa espalhados pelo país, tanto na Ciência Política como na psicologia, tais como o Centro de Estudos do Comportamento Político (CECOMP), da Universidade Federal de Minas Gerais, o Núcleo de Pesquisa sobre América Latina (NUPESAL), da Universidade Federal do 
OLIVEIRA, R. A. A era da democracia confusa: Análise das medidas de adesão à democracia nas pesquisas sobre comportamento político

Rio Grande do Sul, o Grupo de estudos sobre Comportamento Político e Opinião Pública (COMPOP), da Universidade de Brasília e o Grupo de Pesquisa em Comportamento Político (GPCP), da Universidade Federal da Paraíba.

Diferentes temas podem ser tratados nessa área, como comportamento eleitoral, atitudes e valores, confiança interpessoal e avaliação de governo. Há um que se relaciona mais diretamente com os objetivos aqui propostos: os estudos sobre legitimidade democrática, aqueles que analisam a chamada "adesão" ou "apoio à democracia" por parte dos indivíduos. Assim, são estudos que possibilitam classificar e qualificar as democracias contemporâneas através da mensuração de aspectos que julgam ser democráticos. Por isso, é através da avaliação das medidas utilizadas por esses estudos que buscaremos analisar qual democracia eles estão pressupondo que os indivíduos apoiam — se mais procedimentalista ou híbrida.

Vale destacar que, em sua maioria, esses estudos utilizam metodologias de viés mais quantitativo, tendo como fonte de dados os surveys aplicados por organizações internacionais, como o World Valeus Survey (WVS), o Latin America Public Opinion Project (LAPOP) e o Latinobarômetro, que são questionários de livre acesso - como são aplicados em grande parte do globo, pesquisadores de diferentes países utilizam as mesmas questões. Dessa forma, esse tipo de abordagem propiciará uma visão universal da conceituação de "democracia" perante esse tipo de estudo. Iremos nos pautar nos estudos mais recentes sobre adesão à democracia, que estão sendo comumente utilizados para avaliar a sua qualidade (RIBEIRO, 2007; BORBA, 2012; GIMENES, 2012; RIBEIRO; BORBA, 2015).

Parte considerável dos estudos aplica o tradicional indicador: a democracia pode ter problemas, mas é melhor do que qualquer outra forma de governo. Essa questão, que remete à denominada "posição churchilliana", é reconhecida internacionalmente como medida de apoio à democracia como forma de governo (KLINGEMANN, 1999; DALTON, 1999), e está presente em praticamente todos os questionários disponíveis. Por isso, se configura como a primeira medida de avaliação.

Contudo, ao longo dos anos, inúmeras críticas foram feitas à questão churchilliana. Uma delas se refere à sua unidimensionalidade e à simplificação da avaliação sobre o grau de democracia de um país. Em razão disso, alguns autores trouxeram ao debate a necessidade do aprofundamento do modo como a democracia estava sendo avaliada e, por isso, propuseram novas medidas.

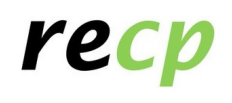


Um dos principais autores sobre legitimidade democrática no Brasil e um dos primeiros a problematizar esse tema é José Álvaro Moisés. Além da construção de novas tipologias, a contribuição mais importante do autor é trazer a ideia de multidimensionalidade para os indicadores de apoio à democracia (MOISÉS, 2008, 2010).

\begin{abstract}
A questão do apoio ao regime tem, portanto, natureza complexa e multidimensional, envolvendo ao mesmo tempo a aceitação da democracia como um ideal, a rejeição maior ou menor de suas alternativas, a insatisfação com seus resultados práticos e atitudes que confundem ou misturam essas escolhas. (MOISÉS, 2008, p. 18).
\end{abstract}

Nesse sentido, a proposta da multidimensionalidade não é apenas uma questão de mensuração: seria um alinhamento entre a visão teórica e a visão empírica sobre a definição de "democracia" (HALL, 2003). Isto porque as escolhas dos indivíduos sobre um regime não são “tudo ou nada”, e sim um processo gradual e ambivalente (MOISÉS, 2010).

Alfredo Alejandro Gugliano (2013) também se preocupou com a coerência entre teoria e prática, e aponta que são muitos os estudos que reduzem a compreensão da democracia e de seus critérios em prol da possibilidade de medi-la quantitativamente, sem problematizarem as limitações de seus resultados. Por isso, não são surpreendentes as diversas críticas que o campo tem sofrido em razão das escolhas de seus indicadores de qualidade da democracia (GUGLIANO, 2013). Assim, Gugliano aponta outros autores, como Corbetta e Peres-Liñan (2001) e Diamond e Morlino (2004), que compartilham o argumento da necessidade de uma ideia mais abrangente de democracia e de que a "qualidade" pode ser composta por diversos predicados.

Booth e Seligson (2009) adotam uma postura crítica quanto às formas convencionais de mensuração da adesão à democracia, destacando dois problemas fundamentais: a priori, devido à expansão da democracia, cada vez mais o termo se mostrou associado a algo positivo, enquanto os regimes autoritários ganharam uma feição negativa. Assim, a democracia passou a ser um regime "socialmente desejável". Dessa forma, a declaração da preferência pelo regime pode refletir muito mais uma resposta socialmente orientada a um termo com conotação positiva do que uma escolha esclarecida (BOOTH; SELIGSON, 2009). A segunda dificuldade estaria no elevado grau de abstração do termo "democracia”, o que dá abertura para inúmeras interpretações, de forma que um único termo passa a significar um conjunto de definições imprecisas que dificultam o real entendimento dos indivíduos sobre seu significado (BOOTH; SELIGSON, 2009). 
OLIVEIRA, R. A. A era da democracia confusa: Análise das medidas de adesão à democracia nas pesquisas sobre comportamento político

Assim como os demais, Norris (1999) e Carlin e Singer (2011) também adotam uma postura de defesa da multidimensionalidade do conceito de "apoio democrático". Os últimos ainda acrescentam que o tipo ideal de democrata coexiste com cidadãos que mantêm sistemas de crenças mistos ou ambivalentes (CARLIN; SINGER, 2011), tanto que em seus estudos dividem o suporte democrático em quatro diferentes dimensões: contestação pública, participação inclusiva, limites de autoridade executiva e instituições e processos políticos (CARLIN; SINGER, 2011). Os autores chegam à conclusão de que tais dimensões são determinadas por fatores e intensidades distintos, sendo algumas pautadas em variáveis culturais e outras no desenvolvimento econômico ou político. Todavia, o mais relevante em seu trabalho é que a adesão à democracia é observada a partir de diferentes enfoques.

A partir da ideia de multidimensionalidade, cresceu a tendência de se propor medidas alternativas às pesquisas mais recentes. Em seus estudos sobre a América Latina, Moisés (2008), para testar sua hipótese, construiu uma tipologia que vai além das atitudes de simples adesão ou rejeição à democracia, como a posição churchilliana. Deste modo, buscou caracterizar o fenômeno da ambivalência política ${ }^{8}$ nas sociedades e seus efeitos para a legitimação da democracia. Assim, adota dois indicadores de adesão à democracia, produzidos pelas seguintes questões: 1) Você concorda muito, concorda, discorda ou discorda muito que a democracia pode ter problemas, mas é o melhor sistema de governo?; 2) Com qual das seguintes frases você concorda mais: "A democracia é preferível a qualquer outra forma de governo"; "Em algumas circunstâncias um governo autoritário pode ser preferível"; "Para pessoas como eu, dá no mesmo um regime democrático ou não democrático”? (MOISÉS, 2008).

A partir dos resultados, Moisés classificou os indivíduos em autoritários, democratas e ambivalentes. Os primeiros seriam aqueles que, em uma resposta, disseram discordar que a democracia seja a melhor forma de governo, e na outra disseram que tanto faz um regime democrático e um não democrático (MOISÉS, 2008). Já os democratas concordam que a democracia é a melhor forma de governo, assim como acreditam que a democracia é preferível a qualquer outra forma de governo. Por fim, os ambivalentes são aqueles que oscilam em suas respostas e tomam posições intermediárias — ou seja, podem concordar que a democracia é a melhor forma de governo, mas acreditam que em algumas situações um governo autoritário pode

\footnotetext{
${ }^{8}$ Tal ambivalência não significa necessariamente uma atitude de contestação ou oposição ao regime democrático, mas sinaliza a falta de segurança em escolhê-lo como único regime político aceito (CASALECCHI; DAVID; QUARESMA, 2013).
} 
ser preferível ou que tanto faz um regime democrático ou não democrático; ou, no caminho inverso, podem acreditar que a democracia é preferível a qualquer outra forma de governo, mas, em seguida, discordar que ela seja a melhor forma de governo (MOISÉS, 2008).

Assumindo uma estratégia que combina as contribuições dos autores acima mencionados, Fuks et al. (2016) tratam a adesão à democracia não como uma única atitude de preferência pelo regime, mas como múltiplas atitudes que envolvem a adesão a diferentes princípios orientadores do regime democrático. Assim, oferecem uma proposta que vai além da testada por Moisés. Ao invés de observarem a ambivalência a partir de duas perguntas similares sobre adesão à democracia, propõem que ela seja verificada a partir das atitudes das pessoas em relação a diferentes dimensões do regime democrático. O foco deste estudo em específico não está nos cidadãos ambivalentes, e sim nos classificados como "democratas", e em que medidas eles são, ou não, coerentes em suas atitudes quando confrontados com diversas questões (CASALECCHI; DAVID; QUARESMA, 2013).

Em razão disso, propõem a mensuração da adesão à democracia e, consequentemente, à legitimidade dos regimes democráticos, em quatro aspectos: adesão aos procedimentos de escolha; adesão normativa ao voto; adesão à participação de todos; e adesão ao regime democrático partidário. A adesão aos procedimentos de escolha é mensurada através de três perguntas: "Diante de desemprego muito alto seria justificado que os militares tomassem o poder por um golpe de estado?”; “Quando há muito crime seria justificado que os militares tomassem o poder por um golpe de estado?"; "Diante de muita corrupção seria justificado que os militares tomassem o poder por um golpe de estado?"

Para o segundo aspecto, adesão normativa ao voto, foi escolhido o seguinte questionamento: "Existem pessoas que dizem que precisamos de um líder forte, que não seja eleito através do voto. Outros dizem que, ainda que as coisas não funcionem, a democracia eleitoral, ou seja, o voto popular, é sempre o melhor. O que o(a) sr./sra. pensa?"

A terceira dimensão, da adesão à participação de todos, é medida pela seguinte pergunta: “O(A) sr./sra. acredita que em nosso país faz falta um governo de 'pulso firme', ou que os problemas podem se resolver com a participação de todos?” Por fim, a última dimensão, adesão ao regime democrático partidário, é verificada pela utilização de uma medida clássica: "Pode haver democracia sem que existam partidos políticos.' Até que ponto concorda ou discorda desta frase?" 
OLIVEIRA, R. A. A era da democracia confusa: Análise das medidas de adesão à democracia nas pesquisas sobre comportamento político

Para melhor visualizarmos as questões utilizadas para medir a qualidade da democracia através dos estudos acima citados, utilizamos a Tabela 1, com a descrição das dimensões e de suas respectivas variáveis, dos estudos de Moisés (2008) e Fuks et al. (2016).

TABELA 1 - DIMENSÕES DA DEMOCRACIA

\begin{tabular}{c|c}
\hline DIMENSÃO & VARIÁVEL \\
\hline Tradicional/churchilliana & $\begin{array}{c}\text { A democracia pode ter problemas, mas é melhor do que } \\
\text { qualquer outra forma de governo. }\end{array}$ \\
\hline Moisés & $\begin{array}{c}\text { Você concorda muito, concorda, discorda ou discorda } \\
\text { Dimensão 1 }\end{array}$ \\
\hline muito que a democracia pode ter problemas, mas é o melhor \\
sistema de governo?
\end{tabular}

A base de dados utilizada por Moisés (2008) foi o Lationobarômetro, e por Fuks et al. (2016) foi o Barômetro das Américas (LAPOP), o que demonstra que as questões que aparecem na tabela estão presentes nos questionários de surveys comumente utilizados pelos pesquisadores da área de comportamento político (o que tende a criar um padrão de medida mais universal). Contudo, é possível observar que a diferença inicial entre a medida tradicional e as demais é a construção da avaliação do aspecto "apoio à democracia" a partir de mais de uma variável. Entretanto, usar mais de uma variável é sinônimo de multidimensionalidade? Como essas novas medidas se conectam com as teorias democráticas? Afinal, o que elas estão medindo? 


\section{DE QUAL DEMOCRACIA ESTAMOS FALANDO?}

Com o objetivo de responder a grande questão do artigo, na Tabela 2 buscamos estabelecer uma classificação das medidas expostas na seção anterior, a título de exemplo sobre como os estudos sobre comportamento políticos têm mensurado a democracia. Em consonância com as correntes teóricas, a proposta tem dois possíveis modelos de democracia avaliados segundo duas dimensões, uma de caráter procedimental e outra normativa. Assim, o primeiro modelo, aquele que se pauta na avaliação das instituições e em suas formalidades, será chamado procedimental (Schumpeter) — ou seja, aquele que olha para a democracia através dos mecanismos e processos presentes nas práticas políticas e da ausência de sentido normativo. O segundo é aquele que busca avaliar além dos processos, pensando também nos valores democráticos. Assim, olha tanto a dimensão procedimental quanto a normativa, e será chamado de modelo híbrido (Dahl, Tourraine, Pateman e Habermas).

TABELA 2 - MODELO DE DEMOCRACIA DAS MEDIDAS

\begin{tabular}{|c|c|c|}
\hline & \multicolumn{2}{|c|}{ DIMENSÃO DE AVALIAÇÃO } \\
\hline MEDIDAS & PROCEDIMENTAL & NORMATIVA \\
\hline Tradicional/churchilliana & $\mathrm{X}$ & \\
\hline MODELO & \multicolumn{2}{|c|}{ PROCEDIMENTAL } \\
\hline \multicolumn{3}{|l|}{ Moisés } \\
\hline Dimensão 1 & $\mathrm{X}$ & \\
\hline Dimensão 2 & $\mathrm{X}$ & \\
\hline MODELO & \multicolumn{2}{|c|}{ PROCEDIMENTAL } \\
\hline \multicolumn{3}{|l|}{ Fuks et al. } \\
\hline Adesão aos procedimentos de escolha & $\mathrm{X}$ & \\
\hline Adesão normativa ao voto & $\mathrm{X}$ & $\mathrm{X}$ \\
\hline Adesão à participação de todos & & $\mathrm{X}$ \\
\hline Adesão ao regime democrático partidário & $\mathrm{X}$ & \\
\hline MODELO & \multicolumn{2}{|c|}{ HÍBRIDO } \\
\hline
\end{tabular}

FONTE: A autora (2017)

A categorização de cada dimensão foi realizada de acordo com os apontamentos teóricos já elucidados na primeira seção. A priori, quando foram iniciados os estudos a respeito da qualidade da democracia e passou-se a utilizar a adesão como medida, esta tinha como pressuposto representar o apoio ao regime democrático enquanto conjunto de regras, princípios e valores — ou seja, dizia respeito à aceitação do regime enquanto ideal político normativo 
OLIVEIRA, R. A. A era da democracia confusa: Análise das medidas de adesão à democracia nas pesquisas sobre comportamento político

(NORRIS, 1999). A posição churchilliana foi pensada como medida de apoio à democracia no que se refere diretamente à dimensão abstrata ou normativa da cultura política (KLINGEMANN, 1999; DALTON, 1999). Entretanto, as pesquisas mais recentes argumentam que a natureza da medida churchilliana estaria se tornando "instrumental" ao invés de "intrínseca". Assim, não seria mais suficiente para captar os valores enraizados nas crenças e na cultura política dos indivíduos. Isto porque a adesão à democracia não depende apenas da rejeição de um regime, mas sim de avaliações mais conjunturais e subjetivas dos cidadãos (BRATTOM; MATTES, 2007; MOISÉS, 2008). Portanto, a dimensão tradicional, atualmente, possui um caráter unidimensional da democracia, definindo-a apenas como uma forma ou sistema de governo, não conotando um caráter mais normativo - o que a classifica como um modelo instrumental.

Apesar de Moisés $(2008,2010)$ argumentar a favor da multidimensionalidade, ainda se percebe que suas medidas não ultrapassam a dimensão dos procedimentos, apresentando apenas outra forma de medir o que tradicionalmente já se faz ${ }^{9}$. As duas dimensões propostas caem na ideia de rejeição de um regime e no argumento de Booth e Seligson (2009) sobre ser um regime "socialmente desejável". Com isso, a proposta de Moisés seria uma tentativa de multidimensionalidade, mas não em termos de relacionar a democracia a procedimentos e valores, e sim de utilizar mais variáveis, mesmo que a essência delas seja a mesma. Dessa forma, classificamos seu modelo como procedimental.

Já a proposta de Fuks et al. (2016) segue a tendência das novas pesquisas e busca aderir aos pressupostos de avaliação de diferentes medidas. Incialmente, a primeira tipologia, segundo os próprios autores, retoma uma definição minimalista da democracia, que é a existência de eleições livres e competitivas para a escolha dos cargos de liderança (FUKS et al., 2016; CASALECCHI; DAVID; QUARESMA, 2013). Assim, qualquer regime que não satisfaça essa condição é classificado como "outro", que não uma democracia, o que evidencia o caráter procedimental da democracia,

O segundo e o terceiro aspectos podem parecer semelhantes, mas, segundo os autores, se diferenciam em relação aos seus objetos. Por um lado, a dimensão adesão normativa ao voto tem como foco o momento eleitoral, mas não o traz com um caráter procedimental, como parte do

\footnotetext{
${ }^{9}$ É preciso esclarecer que este argumento não afirma que o conceito de "democracia" do autor seja procedimental. Ao contrário, sua crítica inicial é justamente pela mensuração unidimensional de um conceito tão plural. Apenas classificamos como de caráter procedimental as variáveis utilizadas. Moisés é um dos pioneiros na ideia de mensuração multidimensional do conceito de "apoio à democracia", e nosso objetivo é demonstrar que mesmo com o acréscimo de variáveis a essência destas permanece na avaliação de algum procedimento do processo político.
} 
sistema, e sim como forma de participação política dos cidadãos. Apesar da explicação dos autores nos levar a categorizá-lo como híbrido, o voto permanece sendo um instrumento - ou seja, essa dimensão consegue ser vista como participante dos dois modelos, uma vez que para o próprio Dahl o voto teria esse caráter.

Por outro lado, para a dimensão da participação política (terceira parte), o objeto de valoração não é o voto enquanto prática, mas sim a participação mais ampla do cidadão na esfera política para atuar como agente político em razão de seus interesses e demandas (FULK et al., 2016; CASALECCHI; DAVID; QUARESMA, 2013). Assim, diz respeito à participação coletiva de uma maneira geral, com a possibilidade de o cidadão utilizar qualquer mecanismo de participação em qualquer momento de sua vida, não só no momento eleitoral. Apesar do seu caráter mais generalista, a pergunta visa, justamente, contrapor a necessidade de um governo pulso firme (e, portanto, de tendência mais autoritária) à participação coletiva, classificando-se essa dimensão como normativa, por valorizar questões substanciais e processuais.

Por fim, a última dimensão refere-se ao papel assumido pelos canais representativos no processo democrático, em especial no que se refere aos partidos políticos. Tais partidos não se apresentam somente como formas de expressão das ideias e ideologias políticas de grupos, mas servem também para a organização e o funcionamento de uma democracia representativa moderna. Nesse caso, independentemente de posições ideológicas e partidárias, os partidos políticos são peças fundamentais da engrenagem democrática moderna. No que se refere às atitudes políticas, ainda que as pessoas não gostem de um ou outro partido, ou até mesmo de nenhum deles, elas reconhecem a sua necessidade e, mais do que isso, o seu caráter indispensável ao exercício democrático. Dito isso, a classificação se encontra na dimensão procedimental, uma vez que o caráter dos partidos, aqui, está sendo visto como um requisito para o formato da democracia, e não como gerador e expositor de ideias ou princípios.

Dessa forma, a proposta metodológica de Fuks et al. (2016) atinge a ideia de um modelo híbrido de democracia, por avaliar tanto a dimensão procedimental quanto a normativa. Isto seria um exemplo de como mensurar um aspecto de maneira multidimensional, ou seja, avaliando diferentes dimensões e não apenas incluindo mais variáveis no modelo. Apesar de suas limitações referentes às questões disponíveis no questionário, é relevante ressaltar o esforço dos autores em transcender a tradição e realmente procurar entender e definir a democracia de maneira mais ampla e plural. Em termos estatísticos, pode ser que essas medidas não se acoplem em uma única 
OLIVEIRA, R. A. A era da democracia confusa: Análise das medidas de adesão à democracia nas pesquisas sobre comportamento político

variável na construção de um índice, mas isso não as impossibilita de serem utilizadas como aspectos a serem mensurados.

Os apontamentos e a classificação realizados acima nos levam, em primeiro lugar, a demonstrar a complexidade de se mensurar uma definição teórica de um objeto tão complexo como a democracia. A dificuldade cresce, já que o objetivo, aqui, é tentar atingir as bases concretas e abstratas do sistema através de uma avaliação de qualidade que não se dê de forma direta. Ainda, foi possível observar que a dificuldade em captar seus aspectos subjetivos deixa aos pesquisadores a alternativa de se avaliar aspectos mais estruturais da democracia. Portanto, a maioria das medidas analisadas pode ser situada no modelo teórico procedimental, por colocarem em destaque a forma e o molde com o qual a democracia deve ser estruturada.

Entretanto, os acontecimentos da sociedade têm mobilizado tanto a teoria quanto a empiria a incorporarem novos aspectos, o que adere mais complexidade aos fenômenos, como propuseram Fuks et al. (2016). Assim, pensar a democracia como fenômeno multidimensional é dar evidencia e autonomia para cada elemento que a constitui, sem que haja a necessidade de se oporem, como alguns teóricos propõem. O ponto mais importante que queremos elucidar é a desconexão entre o caminho da teoria política na busca por pensar a democracia de forma mais plural, resgatando a relevância da combinação entre processo, regras, valores e direitos para a formação de uma sociedade democrática, e o que têm feito as pesquisas empíricas, que, por mais que fiquem atreladas ao que os questionários disponibilizam, ainda caem em avaliações mais procedimentais e, assim, enquadram, erroneamente, sociedades e indivíduos como democráticos ou não.

O quadro que foi aqui exposto não é uma análise pessimista ou negativa sobre as pesquisas empíricas, mas sim uma observação sobre a importância de se repensar tais mensurações. Esse é um movimento exemplificado tanto por Moisés (2008) quanto por Fuks et al. (2016), de trazer a multidimensionalidade como algo que deve estar atrelado à ontologia da área do comportamento político e que se reflete na prática de pesquisa. Portanto, falar em multidimensionalidade não é apenas aumentar o número de variáveis, mas sim captar aspectos normativos e procedimentais de um regime democrático, sendo que, dessa forma, é possível dar respostas às críticas sobre os indicadores de legitimidade democrática e caminhar para um alinhamento entre pesquisas teóricas e empíricas. 


\section{CONSIDERAÇÕES FINAIS}

A democracia tem se firmado como a principal forma de governo no ocidente e, por isso, suas instituições e pressupostos são alvos constantes nas análises políticas. Por conta disso, as pesquisas acadêmicas (teóricas e empíricas) estão cada vez mais preocupadas com elementos democráticos específicos e não com a democracia em si. Essa seleção de objetos tem reforçado a construção de um consenso falso sobre o que é democracia, dando-lhe uma conotação que não é unificada nem consensual. Entretanto, isto não significa que haja a necessidade da existência de um padrão, já que a democracia implica uma complexidade de valores, elementos e organizações, não havendo um tipo único que a exemplifique.

A falta de atenção dada a este requisito por parte das análises tem afastado os debates sobre a conceituação da democracia. De um lado, as teorias democráticas contemporâneas se debruçam sobre elementos como "representação" e "participação" e, do outro, as pesquisas empíricas buscam mensurar a qualidade da democracia, sua adesão e os desdobramentos da participação ou representação. Sendo assim, o debate sobre a formulação do regime democrático realizado antes do século $\mathrm{XX}$, quando se iniciou a democratização, tem sido escasso, e isto conduz para a falsa ideia de efeito globalizante do termo "democracia".

Dessa forma, este artigo se estruturou sobre a preocupação com o horizonte da democracia dentro da Ciência Política, pela forma como ela está sendo avaliada. As abordagens empíricas apresentadas expressam visões mais unidimensionais, ao mensurar a adesão pautada em requisitos procedimentais. As pesquisas aqui utilizadas para avaliação são alguns dos exemplos que poderiam ser mostrados, mas outros autores também se propuseram a pensar novas medidas. O que vale ressaltar é a pretensão de se criar um panorama que possa ajudar a situar pesquisadores do comportamento político sobre os caminhos metodológicos que estão se traçando e, além disso, de se demonstrar que o descompasso da teoria democrática, preocupação de muitos críticos, pode estar tomando outros rumos. Assim, novamente, a busca pela multidimensionalidade não trata apenas de novas variáveis, mas da retomada de conceitos e

pressupostos teóricos como fundamentos para pensarmos a construção dos aspectos que se pretende analisar.

Diante disso, o que se expôs ao longo do artigo, por um lado, é que a teoria e a empiria caminham juntas, e que as teorias democráticas contemporâneas têm grande impacto sobre o

\section{recp}


OLIVEIRA, R. A. A era da democracia confusa: Análise das medidas de adesão à democracia nas pesquisas sobre comportamento político

modo como as análises se constituem. Por outro lado, o modo como a teoria é apropriada pela pesquisa empírica afasta suas trajetórias, já que a democracia é privada de seu caráter normativo. Isto corresponde a um problema com a hegemonia de determinados conceitos e padrões metodológicos e tem influenciado na maneira como a qualidade da democracia tem sido avaliada. Sendo assim, as categorias analíticas têm apresentado visões unidimensionais de fenômenos que são claramente complexos e multidimensionais.

Assim, fica demonstrado que autores como Schumpeter são fortemente criticados por suas propostas empíricas de definição de democracia, mas que, ao analisarmos as variáveis utilizadas para medir a democracia e a participação, são os seus modelos os mais aplicados pelos questionários - o que demonstra a restrição da democracia por parte das pesquisas empíricas ao seu formato e a um modelo ideais, mesmo com as novas propostas de mensuração.

Esses aspectos apontam para limitações da aplicabilidade empírica, pois não se consegue alcançar as diferentes dimensões da democracia. Entretanto, isto não a desqualifica: apenas demonstra que devemos reavaliar o modo como tem sido utilizada e procurar abranger os aspectos substantivos dos fenômenos. O principal apontamento que se pode fazer sobre esse assunto diz respeito ao modo como estamos lidando com a democracia: estamos banalizando esse conceito, e o que tem faltado não é apenas a adaptação da pesquisa empírica, mas também da teoria, que deve procurar se reestruturar, visando os desafios que estão sendo colocados pelos contextos atuais. A ideia é constituir medidas mais apropriadas para englobar as complexidades da democracia, não se referindo à construção de padrões e nem silenciando significados. Seria o que Peter Hall (2003) chama de alinhamento entre ontologia e metodologia, a coerência entre o sentido abstrato e o descritivo advindos da empiria. Sendo assim, estas considerações aqui propostas não são retrocessos teóricos ou práticos, mas apenas ajustes às demandas da realidade.

\section{REFERÊNCIAS BIBLIOGRÁFICAS:}

BACHRACH, P. Crítica de la teoría elitista de la democracia. Buenos Aires: Amorrortu, 1973.

BONIFACIO, R. Apontamentos teóricos a respeito do papel da participação política na democracia. Paraná Eleitoral, Curitiba, v. 2, n. 3, p. 387-414, 2013.

BOOTH, J.A; SELIGSON, M.A .The legitimacy puzzle in Latin America: Political Support and Democracy in eight nations. Cambridge, UK: Cambridge University Press, 2009 
BORBA, J. Participação política: a centralidade dos repertórios. Revista Debates, Porto Alegre, v. 6, n. 1, p. 123-147, 2012.

BRATTON, M.; MATESS, R. Learning about Democracy in Africa: Awareness, Performance, and Experience. American Journal of Political Science, v. 51, n. 1, p. 192-217, 2007.

CARLIN, R. E. \& SINGER, M. M. Support for polyarchy in the Americas. Comparative Political Studies, v. 44, n. 11,2011, p. 1501-1526

CASALECCHI, G; DAVID, F; QUARESMA, G. Quão democráticos são os democratas brasileiros? Trabalho apresentado no 5. Congresso da Compolítica, Curitiba, 2013. Disponível em: <http://www.compolitica.org/home/wp-content/uploads/2013/05/GT06-Cultura-politicacomportamento-e-opiniao-publica-GabrielAvilaCasalecchi.pdf>. Acesso em: 27 set. 2017.

CORBETTA, J.; PEREZ-LIÑAN, A. Calidad de la democracia: un análisis de la trayectoria argentina. Instituciones y Desarrollo, Barcelona, n. 10, p. 149-169, 2001.

DAHL, R. Poliarquia. São Paulo: Edusp, 1997.

La Igualdad política. Buenos Aires: Fondo de Cultura Económica de Argentina, 2008

DALTON, R. J. Political Support in Advanced Industrial Democracies. In: NORRIS, P. (Ed). Critical citizens: global support for democratic government. Oxford: Oxford University Press, 1999. p. 57-77.

DIAMOND, L.; MORLINO, L. The Quality of Democracy: An Overview. Journal of Democracy, Washington, v. 15, n. 4, p. 20-31, oct. 2004.

FUKS, M. et al. Qualificando a adesão à democracia: quão democráticos são os democratas brasileiros? Revista Brasileira de Ciência Política, Brasília, n. 19, p. 199-219, jan. 2016.

GIMENES, E. Democratismo entre atores políticos não estatais: o caso dos dirigentes de entidades sociais do município de Maringá (PR). Em Tese, Florianópolis, v. 9, n. 1, p. 39-56, 2012.

Engajamento político: aspectos teóricos e rendimentos empíricos na América Latina. Opinião Pública, Belo Horizonte, v. 7, n. 4, p. 62-71, 2015.

GUGLIANO, A. Apontamentos sobre o conceito de qualidade da democracia. Revista DEBATES, Porto Alegre, v. 7, n. 1, p. 229-243, 2013.

HABERMAS, J. Três modelos normativos de Democracia. In: A inclusão do outro. Rio de Janeiro: Tempo Brasileiro, 2001.

HALL, P. Aligning Ontology and Methodology in Comparative Politics. In: MAHONEY, J.; RUESCHEMEYER, D. (Ed.). Comparative Historical Analysis in the Social Sciences. Cambridge: Cambridge University Press, 2003. p. 373-404. 
OLIVEIRA, R. A. A era da democracia confusa: Análise das medidas de adesão à democracia nas pesquisas sobre comportamento político

KLINGEMANN. H. Mapping Political Support in the 1990s: a Global Analysis. In: NORRIS, P. (Ed.). Critical citizens: global support for democratic government. Oxford: Oxford University Press, 1999, p. 31-56.

LAVALLE, A.; VERA, E. A trama da crítica democrática: da participação à representação e à accountability. Lua Nova, São Paulo, n. 84, p. 95-139, 2011.

MIGUEL, Luis Felipe. Democracia e Representação - Territórios em disputa. Editora UNESP, São Paulo, 2014.

MILBRATH. L.; GOEL, M. L. Political participation. Boston: University Press of America, 1965.

MOISÉS, J. Cultura política, instituições e democracia: lições da experiência brasileira. Revista Brasileira de Ciências Sociais, v. 23, n. 66, fev. 2008.

. Os significados da democracia segundo os brasileiros. Opinião Pública, Campinas, v. 16, n. 2, p. 269-309, nov. 2010.

NORRIS, P. Critical Citizens: Global Support for Democratic Government. Oxford: Oxford University Press, 1999.

PATEMAN, C. Participação e teoria democrática. Rio de Janeiro: Paz e Terra, 1992.

RANINCHESKI, S.; CASTRO, H. Democracia, crenças e cultura política na América Latina: da naturalização à construção dos conceitos - uma comparação. Pensamento Plural, Pelotas, v. 11, p. 27-44, 2012.

REIS, Fábio Wanderley. Política e Racionalidade - Problemas de teoria e método de uma sociologia crítica da política. 2a ed. Belo Horizonte: Ed. UFMG, 2000.

RIBEIRO, E. Bases da legitimidade democrática no Brasil: adesão a valores e avaliação de desempenho. Opinião Pública, Campinas, v. 13, n. 1, p. 74-96, 2007.

RIBEIRO, E; BORBA, J. Participação política na América Latina. Maringá: Universidade Estadual de Maringá, 2015.

SARTORI, G. A teoria da democracia revisitada. São Paulo: Ática, 1994. v. 15.

SCHUMPETER, J. Capitalismo, Socialismo e Democracia. Rio de Janeiro: Fundo de Cultura, 1961.

SILVA, D. et al. Teoria Democrática Contemporânea: Modelo Democrático Competitivo e Modelo Democrático Popular. Em Tese, Florianópolis, v. 10, n. 1, p. 1-27, 2013. 
SILVA, R. Duas tensões na teoria democrática. Revista de Ciências Humanas, Florianópolis, p. 41-59, 1999. Edição especial temática.

TOURAINE, Alain. O que é a democracia. Petrópolis: Vozes, 1996

YOUNG, Iris Marion. Inclusion and Democracy. Oxford: Oxford Unversity Press, 2000

Structural Injustice and the Politics of Difference - Paper for the AHRC

Centre for Law, Gender, and Sexuality - Intersectionality Workshop, 21/22 May 2005, Keele University, UK 